ARTICLE

\title{
An update on attention deficit hyperactivity disorder (ADHD)
}

\author{
W Vogel, MB BCh, MMed, FCPsych (SA), Certificate in Child and Adolescent Psychiatry \\ Division of Child and Adolescent Psychiatry, Red Cross War Memorial Children's Hospital, Cape Town, and University of Cape Town, South Africa
}

Corresponding author: W Vogel (wendy.vogel@uct.ac.za)

S Afr Med J 2014;104(1):72. DOI:10.7196/SAMJ.7728

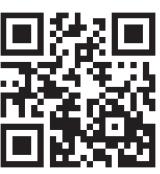

Although the diagnosis of attention deficit hyperactivity disorder (ADHD) attracts much media attention and is seen by many to be a disorder of the 20th century, it was already described in the 18 th century. ${ }^{[1]}$ This article highlights the latest recommendations in the assessment and treatment of ADHD across the age range. It gives an update on the diagnostic criteria for ADHD, which have been revised in the updated Diagnostic and Statistical Manual of Mental Disorders (DSM 5). ${ }^{[2]}$

\section{Prevalence and aetiology}

Prevalence rates are about $5 \%$ for children and adolescents and about $2.5 \%$ for the adult population. ${ }^{[2]}$ The male to female ratio is about $4: 1$. This may be due to girls presenting differently to boys. Girls may be misdiagnosed or under-diagnosed. The exact aetiology of ADHD is unknown. There is a strong genetic association, with multiple genes being implicated (such as DAT1 and DRD4). There is an association with perinatal problems such as prematurity and low birth weight. There is also a strong association with exposure to tobacco smoke in utero. ${ }^{[3]}$

\section{Changes in DSM 5}

ADHD is now classified as a neurodevelopmental disorder. Such disorders typically manifest early in a child's development and produce impairments of social, academic, personal or occupational functioning.

The neurodevelopmental disorders are:

- ADHD

- autism spectrum disorders

- communication disorders

- intellectual disability

- specific learning disability

- motor disorders (tics, stereotypical movement and developmental co-ordination disorder).

Other changes from DSM IV-R:

- Symptoms must be present prior to the age of 12 years (previously 7 years).

- ADHD can be diagnosed with comorbid autism spectrum disorder.

- There is a lower symptom threshold for adults/adolescents (5 symptoms compared with 6).

- Specifiers of presentation (combined type, hyperactive/impulsive type or inattentive type) and severity (mild, moderate or severe). ${ }^{[2]}$

ADHD has three main symptom clusters - inattention, hyperactivity and impulsivity. See Box for DSM 5 diagnostic criteria.

The predominant symptoms of ADHD may vary with age, as shown in Table 1 (adapted from ${ }^{[3]}$ ).
Other symptoms that may be seen, but that are not necessarily part of the diagnostic criteria, include:

- impaired impulse control and the capacity to delay gratification

- inability to stop and think before acting/doing

- social clumsiness

- poor co-ordination

- disorganisation

- forgetting to do things or poor working memory

- delayed development of internal language and rule-following

- difficulties with regulation of emotions, motivation and arousal

- diminished problem-solving ability and flexibility.

\section{How to diagnose ADHD}

There are no diagnostic tests that are pathognomonic for ADHD. A good clinical history and examination are essential. The developmental history should include early childhood development, a psychosocial history and an assessment of co-morbid conditions. Collateral information, particularly from the school, is essential to assess whether ADHD symptoms are present in more than one setting. As ADHD tends to run in families, it is useful to explore the mental health of both parents, including asking about ADHD. A history of cardiac disease in the child and family should be explicitly explored. Sudden unexplained death from possible cardiac causes in family members, a history of exercise syncope, breathlessness or previous cardiac disease in the child will require further detailed cardiac examination prior to starting stimulant treatment for ADHD. Explore the misuse of substances in the child and his/her family.

Rating scales are useful for the assessment, but are not diagnostic tools. The SNAP-IV (Swanson, Nolan and Pelham) rating scale has been used in a number of research trials. It is free and can be downloaded from the internet. ${ }^{[4]}$ Remember to spend time speaking to the child or adolescent.

The physical examination should include weight, height, blood pressure and pulse. Exclude cardiac conditions and thyroid disorders and diabetes.

Once the diagnosis of ADHD has been made, look for comorbid conditions. ADHD seldom occurs as an isolated condition. Always look for comorbid learning difficulties. The other neurodevelopmental disorders, such as autism spectrum disorders, tic disorders and learning difficulties, often occur with ADHD. Anxiety and mood disorders may also complicate the picture.

\section{Women and ADHD}

The male to female ratio of 4:1 may not be an accurate reflection of the true prevalence for girls. Girls present with high levels of inattention. They often show low levels of disruption and hyperactivity and their symptoms may not be obvious. As the environmental demands increase, so may the features of the condition become more obvious. Girls may also present with a less severe form of ADHD. Despite this, 


\section{DSM 5 diagnostic criteria for ADHD}

A: A persistent pattern of inattention and/or hyperactivity-impulsivity that interferes with functioning or development as characterised by inattention and/or hyperactivity/impulsivity.

Inattention $-\geq 6$ of the following (if 17 years or older, only 5 required):

- often fails to give close attention to details or makes careless mistakes

- often cannot sustain attention in tasks or play activities

- does not seem to listen when spoken to directly (mind seems elsewhere)

- often does not follow through on instruction and fails to finish schoolwork (starts tasks and loses focus easily)

- often has difficulty organising tasks and activities

- often avoids or dislikes tasks requiring mental effort

- often loses things

- easily distracted

- forgetful in daily activities.

Hyperactivity and impulsivity - $\geq 6$ of the following (if 17 years or older, only 5 required):

- often fidgets with hands or squirms in seat

- often leaves seat

- often runs or climbs about when inappropriate (adults have inner restlessness)

- unable to play quietly

- is often on-the-go or acts as if driven by a motor

- talks excessively

- blurts out answers before the question has been completed

- often has difficulty waiting his/her turn

- often interrupts or intrudes on others.

B: Several inattentive or hyperactive-impulsive symptoms were present before the age of 12 years (previously 7 years).

C: Several inattentive or hyperactive-impulsive symptoms are present in two or more settings (e.g. at home, school or work or other activities).

D: There is clear evidence that the symptoms interfere with social, academic or occupational functioning.

E: Symptoms do not occur exclusively during the course of schizophrenia or are not better explained by another mental disorder. ${ }^{[2]}$

Table 1. The predominant symptoms of ADHD and age ${ }^{[3]}$

\begin{tabular}{|c|c|c|c|c|}
\hline & Preschool year & Primary school years & Adolescence & Adulthood \\
\hline Inattention & $\begin{array}{l}\text { Short play } \\
\text { Incomplete activities } \\
\text { Not listening }\end{array}$ & $\begin{array}{l}\text { Brief activities } \\
\text { Changes activities } \\
\text { Forgetful } \\
\text { Disorganised } \\
\text { Distracted }\end{array}$ & $\begin{array}{l}\text { Less persistence } \\
\text { Lack of focus on details } \\
\text { Poor planning }\end{array}$ & $\begin{array}{l}\text { Incomplete details } \\
\text { Forgetful } \\
\text { Lack of foresight } \\
\text { Distracted } \\
\text { Disorganised }\end{array}$ \\
\hline Overactivity & Like a whirlwind & $\begin{array}{l}\text { Restless } \\
\text { Hyperactive }\end{array}$ & Fidgety & $\begin{array}{l}\text { Subjective feelings of } \\
\text { restlessness }\end{array}$ \\
\hline Impulsivity & $\begin{array}{l}\text { Does not listen } \\
\text { No sense of danger }\end{array}$ & $\begin{array}{l}\text { Acts out of turn } \\
\text { Interrupts } \\
\text { Intrusive } \\
\text { Thoughtless }\end{array}$ & $\begin{array}{l}\text { Poor self-control } \\
\text { Reckless risk taking }\end{array}$ & $\begin{array}{l}\text { Accidents } \\
\text { Impatience } \\
\text { Premature decision making }\end{array}$ \\
\hline
\end{tabular}

girls respond well to a combination of behaviour modification and medication treatment.

\section{Treatment of ADHD}

The treatment of ADHD includes pharmacological and psychosocial intervention. Treatment interventions are determined by the age of the child and level of severity of the condition.

\section{Psychosocial intervention}

For children under 5 years of age and those with mild ADHD, psychosocial intervention is the treatment of choice. For those with moderate and severe $\mathrm{ADHD}$, it should be offered in addition to medication. Psychosocial intervention includes parenting programmes, working individually and in groups with children with ADHD, incorporating cognitive behavioural therapy, behavioural approaches and social skills training. Parent training/education programmes can be group based or individualised and informed by social learning theory. ${ }^{[5]}$ Although it is recommended that all programmes are evidence based, in practice very few such programmes are available. Where such programmes do not exist, individual work with the parent/ carer and child should focus on improving memory, concentration and relationship-enhancing strategies.

Behavioural approaches use positive reinforcers to enhance appropriate behaviour and consequences that weaken undesirable behaviour. Reinforcers (or rewards) need to be age-appropriate and should follow immediately after the behaviour to be rewarded. 
Attention should be paid to a healthy diet and exercise. There is insufficient evidence to encourage elimination diets or omega3 supplementation. Encourage parents to keep a food diary for a limited period if they believe that certain foods or additives such as colourants affect their child's behaviour. Some children may benefit from allergy checks.

Working with teachers to help them understand ADHD, to provide support and to modify the classroom environment is helpful. Implementing simple strategies such as paying attention to where the child sits, using visual aids, and non-verbal reminders may lead to improvement in symptoms.

\section{Pharmacological intervention}

Medication includes stimulant and non-stimulant medication.

Stimulant medication includes short-acting, intermediate-release and long-acting forms of methylphenidate. Dexamphetamine is not available for use in South Africa.

Short-acting (immediate-release) methylphenidate usually takes effect within 20 - 30 minutes and lasts 3 - 4 hours. Intermediate preparations, such as long-acting methylphenidate, last for 8 hours and the long-acting, extended-release preparation (Concerta $\mathrm{XL}$ ) lasts for 12 hours. Prescribers should be familiar with the pharmacokinetic profiles of all ADHD treatments to tailor treatment to individual need. ${ }^{[5]}$ Methylphenidate is a controlled medication. The maximum daily dose is $1 \mathrm{mg} / \mathrm{kg} /$ day up to $60 \mathrm{mg} /$ day. Any dose used above $60 \mathrm{mg}$ is off license. ${ }^{[6]}$

Non-stimulant medication licensed for use in ADHD is atomoxetine.

Atomoxetine is a selective noradrenaline reuptake inhibitor (SNRI), which may cause a secondary increase in dopamine levels. It is useful in the treatment of patients with ADHD and comorbid anxiety disorders and in those with a history of substance misuse (diversion). Compared with stimulants, it has a slower onset of action but can be taken once daily. The starting dose is $0.5 \mathrm{mg} / \mathrm{kg} /$ day $1.2 \mathrm{mg} / \mathrm{kg} /$ day - maximum $2.1 \mathrm{mg} / \mathrm{kg} /$ day.

Other non-stimulants such as clonidine (alpha-2 agonists) have demonstrated efficacy in the treatment of ADHD. It is used off licence.

According to $\mathrm{NICE}^{[5]}$ the choice of drug treatment is based on:

- comorbid conditions (e.g. tics/epilepsy)

- tolerability, adverse effects

- convenience of dosing (adherence/schools)

- potential for diversion

- patient/parent preference.

If more than one treatment is suitable, prescribe the treatment with the lowest cost.

\section{Side-effects}

Monitor for any potential side-effects prior to starting treatment:

- Loss of appetite, with loss of weight. Measure weight before starting treatment, then every 3 - 6 months.
- Growth delay. Measure height before treatment, then every 6 months. Plot weight and height on a growth chart.

- Insomnia. Gather information before treatment, as many children with ADHD have sleep disturbances.

- Cardiovascular side-effects. Monitor blood pressure and pulse every 3 - 6 months. Refer to a cardiologist prior to starting treatment if there is a family history of sudden death, cardiomyopathy, symptoms of breathlessness or exercise syncope in the patient.

- In addition to the above, atomoxetine may cause hepatotoxicity and/or an increase in hepatic enzymes, bilirubin and jaundice.

- Atomoxetine may lead to emergent suicidal behaviours.

\section{When to refer to a psychiatrist}

- if unsure of diagnosis

- if parents request a second opinion

- if child is younger than 6 years

- if complex diagnoses (such as ADHD with tics/obsessive compulsive disorder/depression)

- if maximum daily dose of $1 \mathrm{mg} / \mathrm{kg} /$ day methylphenidate has been reached

- if poor response to treatment.

\section{Summary}

- ADHD is a complex condition, often presenting with comorbid conditions.

- The costs of untreated ADHD may lead to substance misuse, poor occupational performance and marital disharmony.

- There is, however, effective treatment available for which there is a considerable evidence base.

- Medication treatment is simple and effective, but the added advantages of giving psychological interventions as well as medication cannot be underestimated.

\section{References}

1. Klaus W, Lang S, Reich KM, Lange LT, Oliver T. The history of attention deficit hyperactivity disorder. Attention Deficit and Hyperactivity Disorders 2010;2(4):241-255. [http://dx.doi. disorder. Attention Deficit and Hyperactivity Disorders 2010;2(4):241-255. Thttp://dx.doi. org/10.100//s12/02-010-0045-8]

2. American Psychiatric Association. Diagnostic and Statistical Manual of Mental Disorders. 5th ed. Arlington, VA: American Psychiatric Association, 2013.

3. Tais SM, Aline JMC, Rachel EV, Joaquín F, Guilherme VP. Attention deficit hyperactivity disorder. In: Rey JM, ed. IACAPAP e-Textbook of Child and Adolescent Mental Health. Geneva: International Association for Child and Adolescent Psychiatry and Allied Professions, 2012 http://iacapap.org/iacapap-textbook-of-child-and-adolescent-mental-health (accessed 25 October 2013).

4. SNAP-IV. http://www.adhd.net/snap-iv-form.pdf (accessed 25 October 2013).

5. National Institute for Health and Clinical Excellence. Attention deficit hyperactivity disorder Diagnosis and management of ADHD in children, young people and adults. NICE clinical guideline 72 guidance. http://www.nice.org.uk/cg72 (accessed March 2013).

6. Rossiter D, ed. South African Medicines Formulary. 9th ed. Rondebosch: Health and Medical Publishing Group of the South African Medical Association, 2010.

\section{Further reading}

Children's books:

- Weaver C. Full of Beans. Australia: Shrink-Rap Press, 1998.

- Yemula CR. Everything a Child Needs to Know About ADHD. 2nd ed. UK: ADDISS, 2007. 